\title{
The Tweed Triangle in a Large Sample of Normal Individuals
}

\author{
CHARLES J. KOWALSKI and GEOFFREY F. WALKER \\ Department of Oral Biology, School of Dentistry, University of Michigan, \\ Ann Arbor, Michigan 48104, USA
}

\begin{abstract}
The Tweed triangle (Angle Orthodont 24:121$169,1954)$ has been a useful guide in orthodontic diagnosis and treatment planning. The angles that form the triangle are the Frankfort horizontal-mandibular plane (FH/MP) angle, the lower incisor-mandibular plane (LI/MP) angle, and the Frankfort horizontal-lower incisor (FH/LI) angle. Tweed suggested that the respective "ideal" values for these measurements were $25^{\circ}, 90^{\circ}$, and $65^{\circ}$. He studied the distributions of these measurements in a sample of 45 individuals that had good, rather than ideal, balance of facial outline and found average values of $24.9^{\circ}, 86.6^{\circ}$, and $68.6^{\circ}$. Downs (Amer J Orthodont 34:812-840, 1948) had studied the distributions of these variables in 20 individuals from 12 to 17 years of age, and about equally divided with respect to sex, that had clinically excellent occlusions. He found respective mean values of $21.9^{\circ}$ (from $17^{\circ}$ to $28^{\circ}$ ), $91.4^{\circ}$ (from $81.5^{\circ}$ to $97^{\circ}$ ) and $66.7^{\circ}$ (by subtraction). Values of this order are generally accepted as normative values for these measurements, despite the fact that they are based on small samples from special populations, with little attention to possible sexual dimorphism and the dependence of these measurements on age (growth). Recognizing these problems, Kowalski and Walker ( $J$ Dent Res $\mathbf{5 0 : 9 8 4 , 1 9 7 1 )}$ conducted a study of 474 "normal" males and 630 "normal" females, and found that the mean of the LI/MP angle is close to $97^{\circ}$ in the 12 to 17 year age bracket
\end{abstract}

Additional information available on request to authors.

Received for publication April 26, 1971. (the age interval studied by Downs). In this paper the triangle is completed by a report of the corresponding data for the distribution of the FH/MP angle.

Cephalometric data obtained from radiographs of children with normal dental occlusion were part of a survey of normal growth (conducted at the Philadelphia Center for Research in Child Growth). Data were processed by the mathematical model for craniofacial morphology developed by G. F. Walker (New Zeal Dent J 63:31-38, 1967), and the descriptive statistics for the distribution of the $\mathbf{F H}$ / MP angle are given in the table. The table shows a tendency for the FH/MP angle to decrease with increasing age. No sexual dimorphism is evident except in the 18 to 26 age group, but the sample group for this age was relatively small. In the age group studied by Downs (12 to 17 years), our mean is $24^{\circ}$, as compared with Downs' mean of $22^{\circ}$ and Tweed's ideal of $25^{\circ}$. These differences in mean values are not great, but the dependence of the FH/MP angle on age may be of considerable importance in orthodontic diagnosis and treatment planning.

By subtraction, we may make certain inferences about the distribution of the FH/LI angle in the population studied. For the 12 to 17 year age group, our sample shows an FH/LI angle of $59^{\circ}$, as compared with Downs' mean of $66.7^{\circ}$ and Tweed's ideal of $65^{\circ}$. This angle tends to increase with increasing age to balance the corresponding decrease in the FH/MP angle (the LI/MP angle remains relatively constant throughout growth). The adult mean values are only $61^{\circ}$, a considerable difference from the values reported by Downs and Tweed.

TABLE

Distrubution of the Frankfort Horizontal-Mandibular Plane ANGle in 474 Normal Males and 630 Normat Females

\begin{tabular}{|c|c|c|c|c|c|c|c|c|c|c|}
\hline \multirow[b]{2}{*}{ Age } & \multicolumn{5}{|c|}{ Males } & \multicolumn{5}{|c|}{ Females } \\
\hline & $N$ & Mean & SD* & Minimum & Maximum & $N$ & Mean & SD & Minimum & Maximum \\
\hline 6-8 & 21 & 28.52 & 5.76 & 18.62 & 42.58 & 36 & 26.72 & 4.61 & 12.07 & 33.10 \\
\hline $8-10$ & 73 & 26.54 & 4.14 & 15.29 & 34.88 & 104 & 26.86 & 5.64 & 7.38 & 39.03 \\
\hline $10-12$ & 114 & 25.66 & 3.85 & 15.73 & 37.91 & 153 & 25.34 & 6.62 & 5.09 & 36.12 \\
\hline $12-14$ & 124 & 24.88 & 3.90 & 13.25 & 35.13 & 159 & 24.96 & 5.44 & 8.55 & 35.76 \\
\hline $14-16$ & 85 & 24.05 & 4.81 & 13.02 & 37.20 & 106 & 24.09 & 5.99 & 8.95 & 36.15 \\
\hline $16-18$ & 35 & 23.57 & 6.74 & 5.14 & 40.08 & 58 & 23.10 & 4.91 & 11.47 & 34.67 \\
\hline $18-26$ & 22 & 20.79 & 6.30 & 13.65 & 35.82 & 14 & 25.85 & 5.90 & 13.65 & 30.87 \\
\hline
\end{tabular}

